\title{
Analysis of City Marathon Event Holding Mode Based on Market-oriented Operation
}

\author{
Wu Fengzhen ${ }^{1}$, Fu Mengning ${ }^{2}$, Qi Tiechen ${ }^{3}$, Liu Kefu ${ }^{4}$ \\ ${ }^{1}$ Wu Fengzhen (1997-), female, undergraduate, a 2017 economics student of Huali College, Guangdong University of \\ Technology. \\ ${ }^{2}$ Fu Mengning (1998-), female, undergraduate, a 2017 student of economics from Huali College, Guangdong \\ University of Technology. \\ ${ }^{3}$ Qi Tiechen (1980-), male, library librarian, Master of Information Science, research directions: corporate \\ information activities, library services innovation. \\ ${ }^{4}$ Liu Kefu (1955-), male, professor and master supervisor of the School of Economics and Trade, Guangdong \\ University of Technology. Main research directions: industrial economics, business management. \\ Corresponding author: Qi Tiechen, 13751809675, Email:qitiechen@163.com, Guangzhou Huali Science and \\ Technology Park, Zengjiang Street, Zengcheng District, Guangzhou, HuaLi College GuangDong University of \\ Technology Enterprise Application Information Research Center.
}

\begin{abstract}
In recent years, the City Marathon in China has been developing rapidly, with more than 100 events held each year, and the number of events held and the number of participants has continued to increase. As a competitive and mass event, the marathon has brought greater social and economic benefits to the host city. My country's City Marathon has been running for decades and has achieved great success. However, there are still shortcomings in terms of match operation, operational mechanism, operational management level, and introducing market mechanisms to hold events. This article discusses the development characteristics, marketization operation mechanism and effects of City Marathon in my country, and proposes relevant measures to improve the marketization operation of City Marathon.
\end{abstract}

Keywords: City Marathon, marketization operation, countermeasures

\section{Classification number: G251}

\section{THE OVERVIEW OF THE CITY MARATHON SPORTS IS DEVELOPED IN CHINA}

Since the first Beijing International Marathon was held in Beijing in 1981, the City Marathon became a novel sporting event involving mass participation, and it attracted people's attention. In the past, people could only see famous athletes running marathons in world competitions. Now, not only are many prestigious athletes gathered in one place to compete, many marathon enthusiasts also have a stage to show their advantages. Although the marathon start late in our country, with people's enthusiasm for physical exercise and the continuous improvement of living conditions, this sporting event has become popular in cities. In the following years, City Marathons are successively held in cities such as Hangzhou, Dalian, and Shanghai, which have relatively high economic development levels in my country ${ }^{[1]}$.

In 1995, the State Council promoted the "Outline of the National Fitness Program." As a sport with extensive participation and appreciation, the City Marathon enters a period of rapid development. In order to adapt to the development of this sport, China begin to research and reform the marathon system of match. For example, to encourage all people to actively participate, the event holding breaks the boundary between professional and non-professional to a certain extent, which makes marathon sports better satisfy sports fans need. In 2015, the China Athletics Association announces that it will 
completely cancel the examination and approval of marathon events, decentralize the approval of the holding event. And it also gradually relaxes the access conditions of the event, innovating to the marathon management model. The government's approval of marathon events has mobilized the enthusiasm of social power to hold the event. Therefore, from east to west, from south to north, marathon matches are continuously held by some major cities in China, and it becomes an important event in urban sports and citizens' lives ${ }^{[2]}$.

The City Marathon is introduced from abroad. After decades of exploration and reform, it has become an attractive event brand that combines athleticism and popularity, and has become a characteristic business card of the city. The City Marathon in my country has gradually integrated into the leisure life of the citizens, and its positive, enterprising, healthy and progressive spirit and ideas have continuously penetrated into the hearts of the Chinese.

According to statistics, my country hold 134 events in 2015,993 events in 2016, 1102 events in 2017, 1581 events in 2018, and 1828 events in 2019. The figures reflect the explosive growth of the number of marathon events. The host of the match no longer invests funds unilaterally, but pays more attention to integrating social resources, attracting investor through more channels, diversifying funding sources, and solving the problem of event funding ${ }^{[3]}$. Marketization operation will have specific requirements for match organization, brand promotion, and business investment. With the increase in the number of internationally certified marathons held in my country in recent years, my country must follow corresponding principles and laws in the organization and planning of events.

\section{CITY MARATHON BRINGS SOCIAL AND ECONOMIC BENEFITS}

In China, the City Marathon is oriented by national fitness, and aims to achieve social and economic benefits. In the practice of holding events, reasonable coordination among event organizers, participants, merchants, audiences, potential consumers and city managers form a sports event industry chain, which systematically linking events administration, event operations, event promotion, image and value-added services, event sponsorship, event organization training, event information systems, insurance services, medical rehabilitation and other elements ${ }^{[4]}$.

\subsection{It Is Beneficial To The Growth Of Sports Population.}

Statistics show that between 2015 and 2018, the number of sports population has increased from 1.5 million to 5.83 million. In just three years, the number of sports population has quadrupled. The direct effect of the developing marathon sports is the increase in the sports population and popularity ${ }^{[5]}$. The growth of the sports population first improves the overall physical fitness of the residents and enhances the level of urban spiritual civilization; it effectively stimulates sports consumption, and then promotes the growth of the city's economy. With the development and consolidation of citizens' fitness habits, the increasing demand for related consumption, such as sportswear, sports venues, sports tourism and leisure and so on, which brings some developed opportunities to merchants.

\subsection{It Promotes The Construction Of "Two Civilizations" In The City.}

In 2019, a total of 31 provinces and cities across the country hold in all of 1828 marathon events. Among them, the top six provinces (municipalities) in the country for the number of marathon events are Zhejiang, Jiangsu, Beijing, Sichuan, Guangdong, and Shandong, and the average number of marathon events is held by the six provinces over a hundred games; these six provinces (municipalities directly under the Central Government) total close to one-half of the totality of annual matches in the all country. The location of the marathon event is closely related to the economic development level of the regional city ${ }^{[6]}$. The degree of city economic development determines the acceptability of the marathon and the level of marketization operation. The marketization operation of the marathon event will also reflect the city's economic development and operational capabilities. The construction of spiritual civilization and the material civilization are the two wheels of my country's social development. The spiritual civilization and material civilization are two complementary forces. The City Marathon can embody the connotation of "two civilizations" and enhance the status of the city, thus it is favored by city managers and merchants.

\subsection{It Can Raise The Urban Humanistic Environment.}

From the perspective of the City Marathon, compared with other sports events, long-distance running is a challenge to the physical and psychological limits of people, reflecting the high sports performance of sports enthusiasts, showing the perseverance of participants, demonstrating team spirit and having a unique charm; the competitive marathon requires high physical fitness of participants. It takes a certain amount of talent and hard work to achieve good results, while the threshold of leisure marathon sport is relatively low ${ }^{[7]}$. The men, women, young and old can participate, and the cost is low, because it is no required professional training. It is a popular form of fitness highly recognized by people, a way to prove their own exercise results, and a social form to make friends. Due to the wide 
participation of City Marathon, participants generally have positive character, positive lifestyle and healthy physical fitness. Therefore, this sport has a positive effect on social and economic growth, humanistic quality education, and purification of the social environment ${ }^{[8]}$.

\section{ANALYSIS OF THE HOLDING MECHANISM OF CITY MARATHON EVENTS IN CHINA}

\subsection{Government-Oriented Holding Mechanism}

In the early ages of holding City Marathon in my country, cities applying for such large-scale sports events must be approved by the relevant administrative departments. The access conditions are relatively high and the system lacks flexibility ${ }^{[10]}$. The organization authority of the events is highly concentrated in the government functional departments. Not only does the competition lack a certain degree of efficiency, it is not conducive to the operation of the competition, but it is also unable to effectively attract businesses, which inhibits the enthusiasm of businesses to invest in the competition to a certain extent. The State Council issued a document in 2014, emphasizing the further loose of administration and delegation of power in the hosting of various sports events, boosting the development of the sports industry, promoting sports consumption, and promoting public fitness. Develop a system of streamlining administration, delegating powers, and delegating control, canceling the approval system for commercial and mass sports events, loosening the development of sports events, providing conditions for the participation of social capital, promoting professional sports reforms, and encouraging the development of professional leagues. Revitalize sports resources. Through streamlining administration and delegating powers, the mechanism for hosting sports events has been transformed from a "government-organized" model to a "government-society-enterprise joint organization" model ${ }^{[9]}$.

\subsection{Holding Mechanism Based On Non-Profit Social Groups}

Non-profit social groups and organizations hold City Marathon, focusing on the mass character of the event, without considering the commercial nature, only investing, and not pursuing economic returns. The City Marathon mainly reflects the public welfare. This holding mechanism is conducive to expanding the scale of public participation and reflecting the mass participation and public welfare of sports. But without the support of social funds, the cost of hosting the event will be undertaken by non-profit social organizations, which will face huge financial pressure; most non-profit social groups and organizations are funded by charity sponsorship and charity donations. If the event is held regardless of the economic return, and the production is used to make up for the investment, as well as there will be a situation of making ends meet ${ }^{[11]}$. This situation cannot be carried out for a long time, and the City Marathon cannot have the momentum for development. Generally speaking, non-profit social groups and organizations do not professionally host sports events for a long time, and often lack event hosting experience. If City Marathon become pure public welfare undertakings, it will be difficult to achieve a virtuous cycle and development of such large-scale urban sports.

\subsection{Holding Mechanism Based On Commercial Institution}

Commercial institutions are familiar with the market, value efficiency and input-output, and pay attention to income generation. Commercial institutions hold City Marathon events, which is conducive to the deployment of event resources and getting benefits from events. Commercial institutions pay attention to market-oriented operations, are good at rationally connecting market economy factors with popular sports games, and use sports events to market products from manufacturers, which can achieve good advertising effects and obtain more capital outcome. Generally, large-scale international sports events such as the Olympic Games and the Football World Cup are organized by the government and handed over to the planning and operation of specialized commercial organizations. This has proven to be a successful holding mechanism. Currently, Chinese football, basketball and other sports club leagues are such sports events dominated by commercial organizations. In China, City Marathon races have the characteristics of mass and public welfare. Commerciality and economy should not be put in the first place. It is necessary to organically combine social and economic benefits. This is the fundamental principle that the government and the main organizers of the race should insist ${ }^{[12]}$.

\section{COUNTERMEASURES TO IMPROVE THE MARKETIZATION OPERATION OF CITY MARATHON IN CHINA}

\subsection{Optimize the Government-Led Event Holding Mechanism}

If the authority to hold events is highly concentrated in government departments, the flexibility of holding sports events will be lacking. Reform the government-led event holding mechanism. The main functions of the government are reflected in the organization supervision and the allocation of resources in the large-scale sports events. Only in this way, the 
government will promote the market-oriented operation and industrialization of marathon sports. The holding of large-scale sports events should be led by the government, with the participation of social organizations and commercial organizations. The holding of events cannot be a "solo dance" of the government, but a "group dance" organized and coordinated with a division of labor. Government functional departments can use authorization or use bidding methods to attract social sports institutions or other social commercial organizations to hold marathon events, and establish and improve a mode of running competitions that is mainly governed by government and commercial organizations participate. Strengthen "decentralization, management and service", deepen the market-oriented operation mechanism, and fully mobilize large and well-known enterprises to participate in sports events, achieve "win-win" in commercial operations, and use market means and enterprise professional management models to strengthen event operation and management.

\subsection{Use Event Brands to Attract Merchants to Participate}

From practice, Chinese City Marathon is generally welcomed by sports enthusiasts and citizens. It is also a city-wide and all-member activity regularly launched by the government. Successful sports events have become the business card of urban civilization and economic development. It also provides an opportunity for the organizers and businesses to obtain social and economic benefits. As a brand event with a certain degree of influence and extensive participation in the new era, the City Marathon has played a positive role in improving the spiritual civilization of urban residents, strengthening their physical fitness and economic returns. Organizers should be good at using the social impact of the event to attract business participation, use market mechanisms to increase investment, expand the source of funds for the event, effectively integrate social resources, and give full play to the role of large-scale sports in driving urban economic development.

\subsection{Actively Develops Derivative Products and Improves the Industrial Chain}

An important addition to the market operation of sports events is the exclusive rights of sports development rights, sports services and physical goods, and the design, production and marketing of sports derivative products. This is a method for holding sports events to obtain economic returns and it is also a means to show sports culture. For example, the production and sales of mascots for large-scale sports events, the design and distribution of sports badges, sports pictures and videos, the sales of sports clothing for sports events, the design and production of dolls related to sports events, etc., are all derivative products brought about by sports events. Develop derivative products with a special sport as the theme, which can promote sports, attract consumers' attention, invigorate the consumer market, enhance the sense of participation of consumers, promote sports culture, and make up for the lack of funds of sports event organizers. It also has a good advertising effect on the event itself. Developing sports derivative products, cultivating and extending the industrial chain, can bring new businesses to enterprises and increase social employment. The sports derivatives of large-scale sports events have extensive social influence and have exclusive rights and patent rights. Organizers can transfer product production and sales licenses, transfer patents, etc., to bring continuous economic benefits to events, and manufacturers can also obtain economic benefits through the production and sales of this licensed product, and use large-scale sports events to enhance corporate visibility.

\section{CONCLUSIONS}

Establish and improve the running mechanism that is guided by the government and widely participated by social organizations and commercial institutions. Combining the current industry advantages, industrial scale, service specialization level and accumulated brand effects of the current City Marathon in my country, and it is more important for the City Marathon to provide motivation about healthy development.

\section{ACKNOWLEDGMENT}

Thanks to Professor Liu Kefu, Dean of the School of Economics, Trade and Foreign Languages, Huali College, Guangdong University of Technology, for his careful guidance and revision of the paper.

Thanks to teacher Qi Tiechen from the Research Center of Enterprise Application Information Center, Huali College, Guangdong University of Technology, for providing research suggestions and guidance.

\section{FUND PROJECT}

1.This article is a funded project of the "College Students Innovation and Entrepreneurship Training Program" organized by the Guangdong Provincial Department of Education and major universities in the province. The research result is about "the problems and countermeasures in the industrialization of marathon sports" (project number: 201813656070).

2. The 2016 key platform and scientific research project of the Guangdong Provincial Department of Education "Research on the Integration and Development of Enterprise Information Education and the Construction of Enterprise Management Courses in Colleges and Universities", project number: 


\section{GXJK205.}

3. The Higher Education Teaching Reform Project of the Department of Education of Guangdong Province "Establishment of the Information Literacy Cultivation System of Private College Students-Taking Huali College of Guangdong University of Technology as an Example", publication number: Yuejiao Gaohan [2018] No. 1.

\section{REFERENCES}

[1] Wang Runbin, Xiao Libin. Cancellation of the examination and approval system for sports events from the perspective of governance modernization [J]. Journal of Sports Adult Education, 2015, 31(01): 9-13+95.

[2] Yu Xiqiang. Briefly describe the development status of the sports industry and the improvement of the legal system. [EB/OL]. https://m.sohu.com/a/316738863 120149615.2019. 2019-05-27/2020-5-24

[3] $\mathrm{Fu}$ Zhijuan. Research on the Industrialization Development of China's Urban Marathon [D]. Hunan University of Technology, 2018.

[4] Liu Xueli, Li Pengju, Huang Keke, Wu Hongchun. The impact of urban marathon on the comprehensive level of the city[J]. Sports, 2012(11): 32-33+27.

[5] Qin Xueqin. Chill thinking on China's urban marathon craze_-Based on the realization of urban marathon event organization value[J]. Journal of Nanjing Institute of Physical Education (Social Science Edition), 2017, 31(01): 35-41.

[6] General Office of the State Council. Notice of the General Office of the State Council on Issuing the Outline for Building a Sports Powerful Country. [EB/OL].

http://www.cpad.gov.cn/art/2019/9/5/art_1461_102 921.html. $2019-09-05 / 2020-05-24$

[7] Liu Gen. Research on the organization and management of marathon events in county-level cities in Shandong Province [D]. Qufu Normal University, 2019.

[8] Jin Cang, Chen Fei. Branding organization and management analysis of Zhengkai International Marathon[J]. Sports Science and Technology, 2018, 39(05): 93-95+97.

[9] Zhao Guangde. Research on Wuhan Marathon Event Organization and Management[J]. Contemporary Sports Science and Technology, 2018, 8(31): 250-251.

[10] The first domestic "Marathon Event Organization and Management Regulations" local standard is released[J]. Public Standardization, 2018(07): 38.

[11] Wang Hui. Research on the organization and management of marathon events[J]. Hubei Sports Science and Technology, 2018, 37(07): $579-581+585$.

[12] Zhang Xue. Research on Beijing Marathon Event Organization and Management [D]. Beijing Sport University, 2012. 